WSRC-TR-92-076

\title{
SHIELD VERIFICATION AND VALIDATION REPORT (U)
}

by C. Boman

Westinghouse Savannah River Company

Savannah River Site

WSRC-TR--92-076

Aiken, South Carolina 29808

\section{DISCLAIMER}

\begin{abstract}
This report was prepared as an account of work sponsored by an agency of the United States Government. Neither the United States Government nor any agency thereof, no: any of their employees, makes any warranty, express or implied, or assumes any legal liability or responsibility for the accuracy, completeness, or usefulness of any information, apparatus, product, or process disclosed, or represents that its use would not infringe privately owned rights. Reference herein to any specific commercial product, process, or service by trade name, trademark, manufacturer, or otherwise does not necessarily constitute or imply its endorsement, recommendation, or favoring by the United States Government or any agency thereof. The views and opinions of authors expressed herein do not necessarily state or reflect those of the United States Government or any agency thereof.
\end{abstract}

This paper was prepared in connection with work done under Contract No. DE-AC09-89SR18035 with the U.S. Department of Energy. By acceptance of this paper, the publisher and/or recipient acknowledges the U.S. Government's right to retain a nonexclusive, royalty-free license in and to any copyright covering this paper, along with the right to reproduce and to authorize others to reproduce all or part of the copyrighted paper. 


\section{DISCLAIMER}

This report was prepared as an account of work sponsored by an agency of the United States Government. Neither the United States Government nor any agency thereof, nor any of their employees, makes any warranty, express or implied, or assumes any legal liability or responsibility for the accuracy, completeness, or usefulness of any information, apparatus, product, or process disclosed, or represents that its use would not infringe privately owned rights. Reference herein to any specific commercial product, process, or service by trade name, trademark, manufacturer, or otherwise does not necessarily constitute or imply its endorsement, recommendation, or favoring by the United States Government or any agency thereof. The views and opinions of authors expressed herein do not necessarily state or reflect those of the United States Government or any agency thereof.

This report has been reproduced directly from the best available copy.

Available to DOE and DOE contractors from the Office of Scientific and Technical Information, P.O. Box 62, Oak Ridge, TN 37831; prices available from (615) 576-8401, FTS 626-8401.

Available to the public from the National Technical Information Service, U.S. Def irtment of Commerce, 5285 Port Royal Rd., Springfield, VA 22161. 


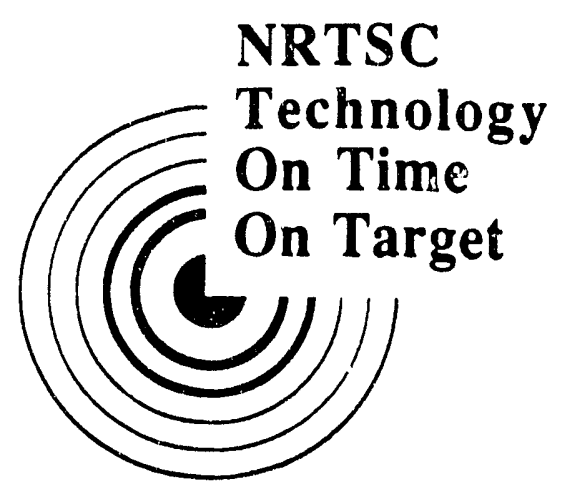

KEY WORDS:

SHIELD

VERIFICATION

VALIDATION

CERTIFICATION

RETENTION PERIOD:

LIFETIME

\section{SHIELD VERIFICATION AND VALIDATION REPORT (U)}

B y

\section{Christa Boman}

ISSUED: February 1992

SRL SAVANNAB RIVER LABORATORY, AIKEN, SC 29808 Westinghouse Savannah River Company

Prepared for the U. S. Department of Energy under Contract DE.AC09-8\$SR18035 
DOCUMENT: WSRC-TR-92.076

TITLE: SHIELD VERIFICATION AND VALIDATION REPORT (U).

TASK: CERTIfication PLAN FOR SHIELd (91-013-1)

APPROVALS

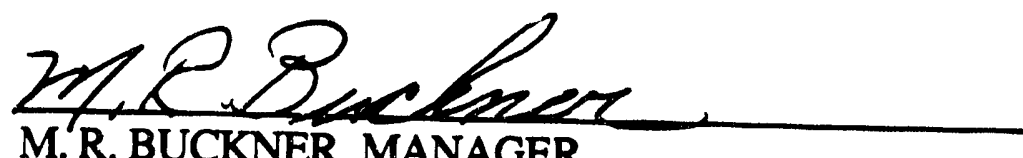

M. R. BUCKNER, MANAGER

DATE $\underline{2-18-92}$

SCIENTIFIC COMPUTATIONS SECTION

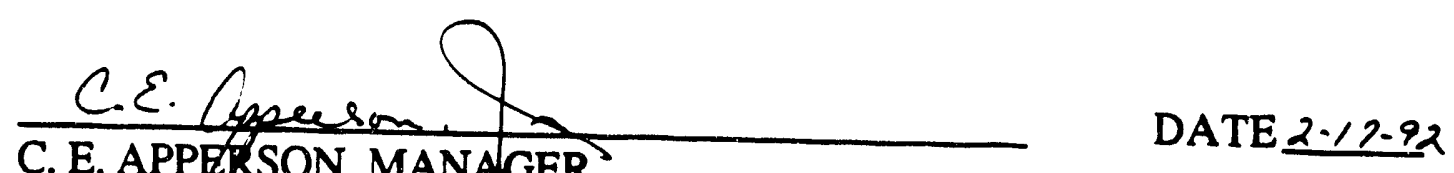

REACTOR PHYSICS GROUP

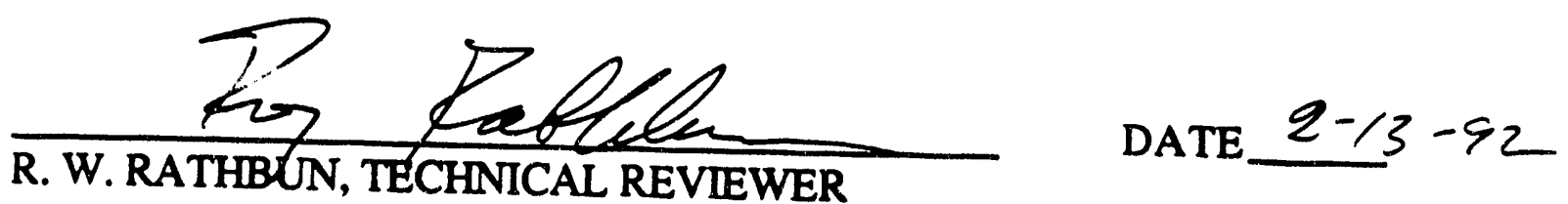




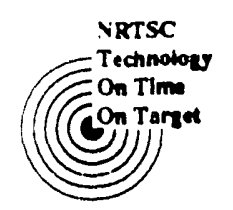

SHIELD Verification and Validation Report

WSR C.TR-92.076

February, $\quad 1992$

- Page 1 of 10

\subsection{INTRODUCTION}

This document outlines the verification and validation effort for the SHIELD, SHLDED, GEDIT, GENPRT, FIPROD, FPCALC, and PROCES modules of the SHIELD system code. Along with its predecessors, SHIELD has been in use at the Savannah River Site (SRS) for more than ten years. During this time the code has been extensively tested and a variety of validation documents have been issued. The primary function of this report is to specify the features and capabilities for which SHIELD is to be considered validated, and to reference the documents that establish the validation. In particular, The SHIELD System User's Manual (Ref. 1), summarizes and quantifies most of the validation documents referenced herein. This verification and validation report only satisfies the requirements for the SHIELD, SHLDED, GEDIT, GENPRT, FIPROD, FPCALC, and PROCES modules of the SHIELD system. It is not a verification and validation of the complete SHIELD system. Complete verification and validation will follow at a later date.

The modules being certified are SHIELD, SHLDED, GEDIT, GENPRT, FIPROD, FPCALC, and PROCES. These modules, the type of calculation they perform, and a one sentence description of their functions are listed in Table 1 below. They are a set of computational modules that provide an accurate calculation of:

(1) Reactor irradiation or burnup;

(2) Isotopic inventory from spontaneous decay;

(3) Isotopic inventory changes from fuel cycle processes; and

(4) Editing.

The system is designed to be applicable to all parts of the nuclear fuel cycle. 


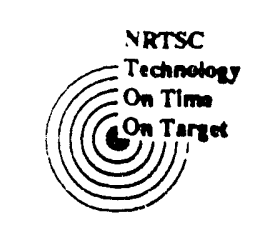

SHIELD Verification and Validation Report

WSR C-TR-92.076

February, 1992

Page 2 of 10

Table 1

\begin{tabular}{|c|c|c|}
\hline Module Name & $\begin{array}{c}\text { Calculation } \\
\text { Type Performed }\end{array}$ & Description \\
\hline SHIELD & & $\begin{array}{l}\text { Controls the flow of all calculat } \\
\text { performed by the SHIELD syste }\end{array}$ \\
\hline SHLDED & & $\begin{array}{l}\text { Controls the flow of EDIT } \\
\text { calculations }\end{array}$ \\
\hline GEDIT & EDIT & Edit calculated results \\
\hline GENPRT & & General edit printing \\
\hline FIPROD & $\begin{array}{l}\text { BURNUP and } \\
\text { COOLING }\end{array}$ & $\begin{array}{l}\text { Stand-alone driver module for } \\
\text { FPCALC production-depletion } \\
\text { module }\end{array}$ \\
\hline FPCALC & BURN: $P$ & $\begin{array}{l}\text { Pointwise production-depletion } \\
\text { calculation for a COOLING time } \\
\text { interval with a pre-specified } \\
\text { flux history }\end{array}$ \\
\hline
\end{tabular}

PROCES SEPARATE

Fuel cycle process simulation

The most fundamental problem solved by the SHIELD system is the time dependent isotopic inventory of a nuclear material as it flows within and between the fuel cycle processes. Historically, computer codes (Refs. 2-5) specific to one part of the fuel cycle have been utilized for this purpose. Most of these codes have a limited range of applicability because of the extensive nuclear data base required (Ref. 6), and the large amount of information at must be communicated from one fuel cycle process to the next. The IELD system brings together computational modules applicable to all parts of the fuel cycle, an extensive nuclear data base, and a communications methodology that permits information flow from 


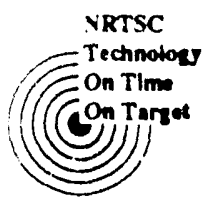

SHIELD Verification and Validation Report

WSRC.TR-92-076

February, 1992

Page 3 of 10

calculation to calculation in different parts of the fuel cycle.

The code is used extensively by the Criticality Methods and Analysis, and Reactor Assistance teams of the Reactor Physics Group, the Core Neutronics Group of the NPR division, and by Reactor Engineering. SHIELD is executed on the IBM 3090 under the JOSHUA operating system (Ref. 7).

The concept for the SHIELD system arose from shielding design and assessment needs of the Converter Fuels Program (CFP), Away From the Reactor Storage (AFR), and Defense Waste Processing Facility (DWPF) programs at the Savannah River Site. Design studies for the SHIELD system were begun in 1976 (Ref. 8), and the first computational modules implemented in 1977. The extensive nuclear data base was implemented between 1976 and 1978 with additions in 1980-1981, and 1987 (Ref. 1). The final computational modules were completed in 1981 .

\subsection{VERIFICATION}

Code verification is the process of confirming that the code functions as intended. Verification encompasses two major categories: underlying theory, and code operation.

The SHIELD code theory documented in Ref. 1 is described in detail in standard nuclear analysis methodology texts such as Refs. 9 \&10. Since no new theoretical development is introduced, the basic theory as documented in the open literature provides conceptual verification of the code theory as required.

After the theory has been verified, it is necessary to confirm that the code correctly implements it, preferably by performing a line-by-line check of the coding. Since SHIELD was developed long before the current quality assurance procedures were in place, the verification performed at the time does not necessarily fulfill current requirements. However, retroactively verifying the coding of a software system the size and complexity of SHIELD would be a monumental task; therefore, it has not been deemed appropriate at this time. Fortunately, the success of SHIELD over the past ten years in predicting isotopic inventory and matching experiments, in 


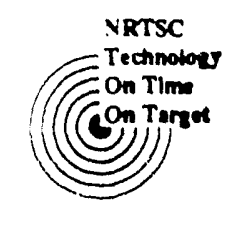

SHIELD Verification and Validation Report

WSRC-TR-92-076

February, 1992

Page 4 of 10

conjunction with the code validation discussed below, are sufficient to confirm that SHIELD correctly implements the theory.

\subsection{VALIDATION}

Code validation is the process of determining how accurately the code models physical reality, and over what range of input values it can be applied. Ideally, the result of the validation is a set of uncertainties and input limitations applicable to specific classes of problems. Due to budgetary constraints, and the fact that new (unanticipated) applications may arise in the future, it is not possible to validate a code of SHIELD's size for every class of problems it will ever be used for. Therefore, the current validation has been performed for a distribution of cases over a range of possible applications. If it becomes desirable to apply the code to a problem that does not fall into one of the validated classes, additional validation for that specific class of problems will be required.

Validation is normally accomplished by comparing code results to actual measured data or exact solutions. When this is impossible or impractical the code results can be compared to the results of calculations with other codes. The latter process is referred to as benchmarking. In the current validation effort, measured data have been utilized when available. Where measured data were not available, benchmarking was employed.

\subsection{VALIDATED FEATURES}

The modules being certified are SHIELD, SHLDED, GEDIT, GENPRT, FIPROD, FPCALC, and PROCES. These are a set of computational modules that provide an accurate calculation of:

(1) Reactor irradiation or burnup;

(2) Isotopic inventory from spontaneous decay;

(3) Is/stopic inventory changes from fuel cycle processes; and

(4) Editing.

Each of these features has been explicitly validated. 


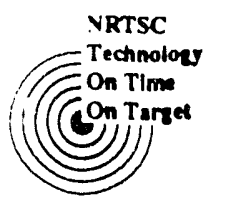

SHIELD Verification and Validation Report

WSR C-TR-92-076

February, 1992

Page 5 of 10

\subsection{DATA LIBRARIES}

Implicit in the validation of any code is the validation of its related data libraries. This is particularly important for SHIELD as it has requires an extensive library of basic nuclear data, conversion factors, quadrature coefficients, atomic masses of nuclides, and other miscellaneous data. All of this information is stored in direct access disk data sets, and is accessed by the JOSHUA data management system using named data record access. The three primary data sets are the MULTIGRP data set, the FISSPROD data set, and the SHIELD data set. Descriptions of the data sets can be found in Ref. 1, The SHIELD System User's Manual.

The SHIELD System User's Manual also documents careful validation studies and independent reviews of the SHIELD system data sets.

\subsection{SUMMARY OF VALIDATION CASES}

The following sections describe the actual calculations used in fulfilling the validation requirements stated above.

\subsection{FIPROD and FPCALC Benchmark Calculations With CINDER and ORIGEN}

A comprehensive benchmarking study of the FIPROD and FPCALC modules of SHIELD using CINDER (Ref. 2) and ORIGEN (Ref. 3), both industrystandard codes, is documented The SHIELD System User's Manual (Ref. 1). Both the LINCHAIN and MATEXP burnup options are validated. These problems are listed as Test Problem No. 1 for the LINCHAIN option, and Test Problem No. 2 for the MATEXP option in Ref. 11.

The SHIELD system modules FIPROD and FPCALC incorporate the mathematical algorithmis of the CINDER code and the ORIGEN code as options in the calculation. The major difference is that the FIPROD-FPCALC calculation in SHIELD uses a common nuclear data base while CINDER and ORIGEN use nuclear data libraries processed to their individual needs. 


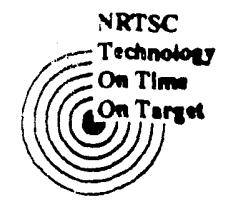

SHIELD Verification and Validation Report

WSR C.TR.92.076

February, 1992

Page 6 of 10

Comparison was made for a 20,000 hour BURNUP calculation of a fuel material similar to a PWR fuel pin operating at 100 watts/cc fission power. The mathematical algorithm chosen is the LINCHAIN option which is essentially the same as the linearized chain methods of the CINDER code. The problem was originally a sample problem for the CINDER code, and extensive comparison of CINDER results to the SHIELD results show agreement to within $\pm 1 \%$, most of this difference arising from using an IBM computer (with shorter word length) rather than a CDC computer. The SHIELD problem is extended to include a 10,000 hour COOLING calculation to compare differences in mathematical algorithms used in the SHIELD calculation. The actual problem appears as Test Problem No. 1 in Ref. 11, and the validation is documented in Ref. 1.

The second comparison problem uses the MATEXP option of the FIPRODFPCALC calculation to calculate the same problem described above. The MATEXP mathematical algorithm is essentially the same as used in the ORIGEN code. The calculated results showed agreement with the original CINDER results to $\pm 1 \%$. This problem appears as Test Problem No. 2 in Ref. 11 , and the validation is documented in Ref. 1 .

\subsection{FIPROD, FPCALC, and EDIT Module Validation With Experimental Data}

The FIPROD, FPCALC and GEDIT modules were also validated with experimental data. Their validations are documented in Refs. $1 \& 12$ and are described here. The modules were validated by comparison to the following experiments:

(1) Fission product energy release for thermal-neutron induced fission of U-235 for various irradiation and decay times. These problems are listed as Test Problem No. 5 and Test Problem No. 7 in Ref. 11. SHIELD calculations of decay heat using ENDFB4 nuclear data were compared to experiment. The data compared were the fission product energy release for thermal-neutron induced fission of U-235 for various irradiation and decay times. For decay times shorter than 15 seconds the calculated results were low by $23 \%$ to $33 \%$. For decay times longer than 15 seconds the calculated results agreed with experiment within $+/-10 \%$ for times up 


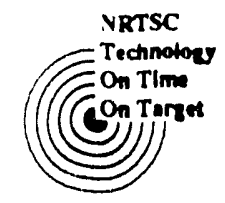

SHIELD Verification and Validation Report

WSR C.TR.92.076

February, 1992

Page 7 of 10

to $1 \times 10^{5}$ seconds. The reason for the systematically low values for times less than 15 seconds is the lack of nuclear data for many short-lived fission products.

(2) Fission product energy release for thermal-neutron induced fission of Pu-239 for various irradiation and decay times. These problems are listed as Test Problem No. 6 and Test Problem No. 8 in Ref. 11. SHIELD calculations of decay heat using ENDFB4 nuclear data were compared to experiment. The data compared were the fission product energy release for thermal-neutron induced fission of $\mathrm{Pu}-239$ for various irradiation and decay times. For decay times shorter than 15 seconds the calculated results were low by $23 \%$ to $33 \%$. For decay times longer than 15 seconds the calculated results agreed with experiment within $+1-10 \%$ for times up to $1 \times 105$ seconds. The reason for the systematically low values for times less than 15 seconds is the lack of nuclear data for many short-lived fission products.

\subsection{PROCES Module Comparison to Hand Calculations}

The PROCES module was used to solve two hypothetical processes. The isotopic inventory results were compared to results from hand calculation (Ref. 13).

The first hypothetical process appears in Test Problem No. 3 in Ref. 11 and is shown in Figure IV-15 in Ref. 1. Comparisons of PROCES results to hand calculations show exact agreement.

The second hypothetical process is more extensive with more detail than the first process. This problem requires iteration of the solution to converge the content of a feedback stream, and appears as Test Problem No. 4 in Ref. 11, and is also shown in Figure IV-15 in Ref. 1. The PROCES results should match the PROCES results from the first process (Test Problem No. 3 in Ref. 11) to within convergence criteria. Ref. 13 documents agreement in results.

Note that although Test Problems No. $3 \& 4$ also access the RADSOR modules, only the PROCES module is being verified and validated in this report. 
WSR C-TR-92.076

SHIELD Verification and Validation Report

February, 1992

Page 8 of 10

\subsection{CONCLUSIONS}

For more than ten years the SHIELD system code has been instrumental in performing reactor irradiation calculations and predicring isotopic inventory at SRS. In this time a substantial number $c$ : validation calculations have been performed. The reports documenting these results serve to establish ranges of validity for the code as described in this document. 
WSR C.TR.92.076

February, 1992

Page 9 of 10

\subsection{REFERENCES}

1. D. R. Finch, The SHIELD System User's Manual, DPSTM-87-700-2, October, 1988.

2. T. R. England, et al., Fission Preduct Data for Thermal Reactors, Part 1: A Data Set for EPRI-CINDER Using ENDF/B-IV, and Part 2: Users Manual For EPRI-CINDER Code and Data. Electric Power Research Institute, EPRI-NP$356,1970$.

3. M. J. Bell, ORIGEN: The ORNL Isotope and Depletion Code, Oak Ridge National Laboratory, ORNL-4628, 1973.

4. W. W. Engle, Jr., A Users Manual For ANISN, Oak Ridge Gaseous Diffusion Plant, K-1693, 1967.

5. K. D. Lathrop and F. W. Brinkley, TWOTRAN-II: An Interfaced, Exportable Version of the TWOTRAN Code For Two-Dimensional Transport, Los Alamos Scientific Laboratory, LA-4848-MS, 1973.

6. D. E. Bartine, et al., Production and Testing of the DNA Few-Group Coupled Neutron-Gamma Cross Section Library, Oak Ridge National Laboratory, ORNL-TM-4840, 1977.

7. H. C. Honeck et al, The JOSHUA System, DPSTM-500, June 1970.

8. D. R. Finch and R. J. Pryor, Program For The Development of a Shielding Computation System for All Phases of Light Water Reactor Fuel Reprocessing, DPST-LWR-76-105, 1976.

9. J. R. Lamarsh, Nuclear Reactor Theory, Addison-Wesley Publishing Co., Reading, MA 1966.

10. Meghreblian and Holmes, Reactor Analysis, McGraw-Hill, New York, NY, 1960. 


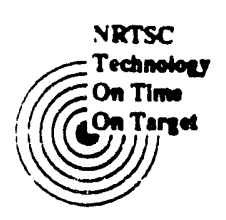

SHIELD Verification and Validation Report

WSRC-TR-92-076

February, 1992

Page 10 of 10

11. C. Boman. A Standard Set of Test Problems for SHIELD, WSRC-TR-92075, February 1992.

12. J. C. Butler and D. R. Finch, A Validation Comparison of SiHIELD System Decay Heat Calculations to Benchmark Quality Experiments, DPST-87-391 (Rev. 1), 1987.

13. A. W. Tipton, SHIELD Proprietor's Notebook, WSRC-NB-90-301.

14. C. E. Apperson, Application of ANS 5.1 to the Evaluation of D:cay Heat Generation in the Mark 16, Mark 31 and Mark 22 Assemblies, D.'S-82423, 1982.

15. C. E. Apperson, Fission Product Activity Data Base for Mark 22, DPST82-687, 1982.

16. C. E. Apperson, Fission Product Activity Data Base for Mark 16B, DPST$83-481,1983$.

17. W. C. Perkins, et. al., Verification of Computer Calculations for Radioactivity in Neptunium Targets, SRL Monthly Report, DPST-83-1-6, 1983. 

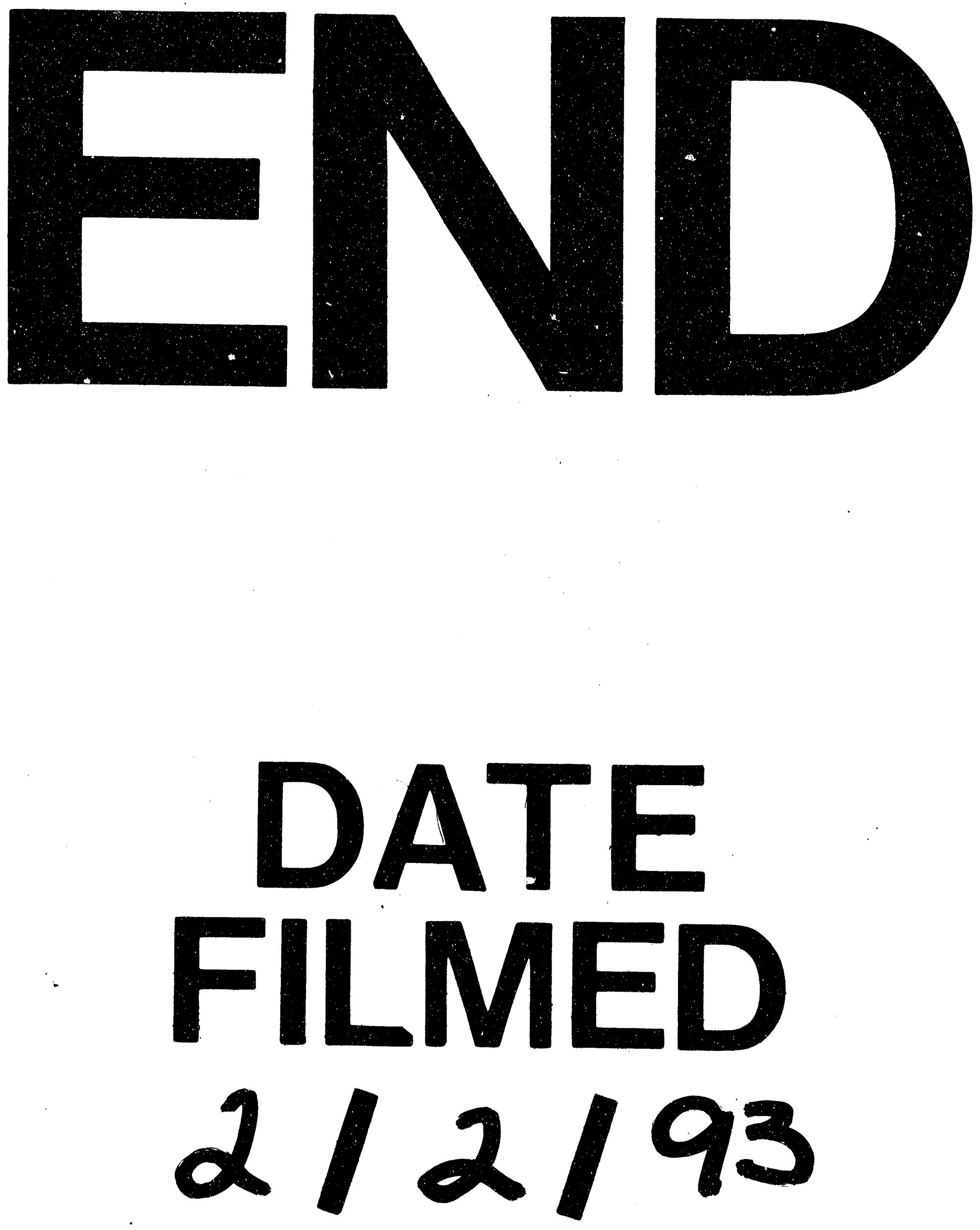
